\title{
Characteristics of diarrheagenic Escherichia coli among children under 5 years of age with acute diarrhea: a hospital based study
}

Yu Zhou ${ }^{\dagger}$ Xuhui Zhu ${ }^{\dagger}$, Hongyan Hou, Yanfang Lu, Jing Yu, Lie Mao, Liyan Mao and Ziyong Sun*

\begin{abstract}
Background: Diarrhea is the leading infectious cause of childhood morbidity and mortality. Among bacterial agents, diarrheagenic Escherichia coli (DEC) is the major causal agent of childhood diarrhea in developing countries, particularly in children under the age of 5 years. Here, we performed a hospital-based prospective study to explore the pathotype distribution, epidemiological characteristics and antibiotic resistance patterns of DEC from < 5-year-old diarrheal children.

Methods: Between August 2015 and September 2016, 684 stool samples were collected from children ( $<5$ years old) with acute diarrhea. All samples were cultured and identified by matrix-assisted laser desorption ionization time-of-flight mass spectrometry (MALDI-TOF MS) and biochemical tests. PCR was used for subtyping, and enteropathogenic E. coli (EPEC) isolates were identified simultaneously with serology. Furthermore, antimicrobial sensitivity tests and sequencing of antibiotic resistance-related genes were conducted.

Results: DEC strains were identified in $7.9 \%$ of the 684 stool samples. Among them, the most commonly detected pathotype was EPEC (50.0\% of DEC), of which $77.8 \%$ were classified as atypical EPEC (aEPEC). Age and seasonal distribution revealed that DEC tended to infect younger children and to occur in summer/autumn periods. Multidrug-resistant DEC isolates were 66.7\%; resistance rates to ampicillin, co-trimoxazole, cefazolin, cefuroxime, cefotaxime, and ciprofloxacin were $\geq 50 \%$. Among 5 carbapenem-resistant DEC, 60.0\% were positive for carbapenemase genes (2 blaNDM-1 and 1 blaKPC-2). Among 30 cephalosporin-resistant DEC, 93.3\% were positive for extended-spectrum $\beta$-lactamase (ESBL) genes, with blaTEM-1 and blaCTX-M-55 being the most common types. However, no gyrA or gyrB genes were detected in 16 quinolone-resistant isolates. Notably, aEPEC, which has not received much attention before, also exhibited high rates of drug resistance $(81.0 \%, 66.7 \%$, and $14.3 \%$ for ampicillin, co-trimoxazole, and carbapenem resistance, respectively).

Conclusions: EPEC was the most frequent DEC pathotype in acute diarrheal children, with aEPEC emerging as a dominant diarrheal agent in central China. Most DEC strains were multidrug-resistant, making even ciprofloxacin unsuitable for empiric treatment against DEC infection. Among carbapenem-resistant DEC strains, those harboring blaNDM-1 and blaKPC-2 were the main causal agents. blaTEM-1 and blaCTX-M-55 were the major genetic determinants associated with high levels of cephalosporin resistance.
\end{abstract}

Keywords: Acute diarrhea, Diarrheagenic Escherichia coli, Antibiotic resistance, Atypical EPEC

\footnotetext{
* Correspondence: zysun@tjh.tjmu.edu.cn

${ }^{\dagger}$ Equal contributors

Department of Laboratory Medicine, Tongji Hospital, Tongji Medical College,

Huazhong University of Science and Technology, No. 1095 Jiefang Road,

Wuhan 430030, China
} 


\section{Background}

Diarrheal disease is the leading infectious cause of childhood morbidity and mortality, most commonly occurring in sub-Saharan Africa and south Asia [1, 2]. China is one of the 15 high-incidence countries, with an annual estimate of 770 million episodes of childhood diarrhea [3]. Although many studies worldwide have reported rotavirus to be the primary cause of acute diarrhea in children, the role of bacteria in causing diarrhea appeared to differ depending on the geographical area [3-5]. Diarrheagenic Escherichia coli (DEC) is the leading cause of bacterial pediatric diarrhea in developing regions [6] and has been suggested to frequently occur in young children [7-9]. Results from a 5-year surveillance in China revealed DEC to be the most common bacterial pathogen among children younger than 5 years of age [4]. However, epidemiological data on DEC is still rare, particularly in China.

On the basis of specific virulence properties, DEC can be classified into 6 major categories: enteropathogenic E. coli (EPEC), enteroaggregative E. coli (EAEC), enterotoxigenic $E$. coli (ETEC), enteroinvasive $E$. coli (EIEC), Shiga toxin-producing E. coli (STEC), and diffusely adherent E. coli (DAEC) [10]. Among these, the first five 5 pathotypes have been frequently studied $[11,12]$. In addition, EPEC can be divided into 2 subtypes according to the presence of bundle-forming pili, a fimbrial adhesin that is a virulence determinant of typical EPEC (tEPEC) but is absent from atypical EPEC (aEPEC) $[13,14]$. While the pathogenic potential of aEPEC strains has been argued in the past, a study published in 2013 by the Global Enteric Multicenter Study indicated aEPEC to be the 5th most frequently detected pathogen in children aged 0-11 months who died of acute gastroenteritis [1]. To date, many severe outbreaks caused by DEC have been reported worldwide and have caused great losses [10].

A multicenter study conducted in China revealed notable differences in DEC categories between populations with different ages [15]. However, information about DEC strains isolated from children with acute diarrhea is sparse, because DEC is not routinely screened in most countries, including China [4]. Many studies have not addressed drug resistance tendency $[15,16]$, but the treatment for infectious agents of the Enterobacteriaceae family has been increasingly complicated by the emergence of strains resistant to most first-line antimicrobial agents in the last few decades [17, 18]. Here, we performed a hospital-based prospective study to explore the pathotype distribution and epidemiological characteristics of DEC from young children with diarrhea, as well as to reveal the grim situation of drug resistance in DEC strains.

\section{Methods}

\section{Clinical definitions}

The definition of diarrhea was as at least 3 abnormal appearance stools (loose, watery, mucus or bloody) in $24 \mathrm{~h}$, with at least one of the following symptoms: nausea, vomiting, abdominal pain, or fever above $37.2{ }^{\circ} \mathrm{C}$. The diarrhea which lasted 14 days or less at the time of presentation was defined as acute diarrhea, otherwise, was defined as persistent diarrhea. Persistent diarrheal Children were excluded from the present study [16].

\section{Study design and population}

From August 2015 to September 2016, stool samples from acute diarrheal children under 5 years of age were collected at Tongji hospital (the largest teaching hospital in central China, which has more than 4000 beds and treats patients from the six surrounding provinces) [19]. All samples were collected under the parents' or legal guardians' permission. Demographic information for each patient, such as age, sex and clinical symptoms were collected.

\section{Identification of $E$. coli}

All stool samples collected were processed by routine microbiological tests to identify. Briefly, MacConkey (Mac) agar were used to isolate the pathogens and incubated for $24 \mathrm{~h}$ at $37{ }^{\circ} \mathrm{C}$. Three suspicious colonies with E. coli morphology (including lac + or lac-) were selected from Mac agar plates and all of them were identified by matrix-assisted laser desorption ionization time-of-flight mass spectrometry (MALDI-TOF MS) using the MALDI Biotyper (Bruker Daltonik GmbH, Leipzig, Germany). Biochemical tests were carried as supplements for E. coli identification. O157:H7 was screened by sorbitol-Mac.

\section{Molecular diagnostic methods for DEC}

DEC was characterized by PCR as previously [19]: tEPEC (eae and $b f p$ ), aEPEC (eae or $b f p$ ), STEC (eae and stx 1 and/or stx2), ETEC (elt and/or estIa or estIb), EIEC (virF and ipaH) and EAEC (aggR and/or pic or astA). The PCR assay was carried out as follow: Boiling method was used for template DNA preparation. PCR was performed in $20 \mu \mathrm{l}$ final volume. The reactions were run with the following cycling conditions: $94{ }^{\circ} \mathrm{C}$ for 2 min, 35 cycles of denaturation at $95{ }^{\circ} \mathrm{C}$ for $20 \mathrm{~s}$, annealing at $60{ }^{\circ} \mathrm{C}$ for $30 \mathrm{~s}$ and primer extension at $72{ }^{\circ} \mathrm{C}$ for $45 \mathrm{~s}$ followed by a final extension at $72{ }^{\circ} \mathrm{C}$ for 5 min. EPEC CMCC44155, ETEC CMCC44815, EIEC CMCC44825 (from the National Institute for the Control of Pharmaceutical and Biological Products in China); EAEC serotype O42, STEC EDL933(from Chinese Center for Disease Control and Prevention) were served as the positive controls. E. coli $\mathrm{DH} 5 \alpha$, which lacks all the diarrhoeagenic genes, was used as a negative control. 


\section{Serotyping}

EPEC serotyping and O157:H7 diagnosis were carried out by slide agglutination test using commercially available antisera (EPEC, O157:H7 antiserum from Ningbo Tianrun Bio-Pharmaceutical Co., Ltd., Zhejiang, China).

\section{Antimicrobial sensitivity test}

Antimicrobial susceptibilities were determined by the agar dilution method according to the Clinical and Laboratory Standards Institute (CLSI) Guidelines, 2015 [20]. All isolates of DEC were tested for their minimum inhibitory concentrations (MICs) of ampicillin, cefazolin, cefuroxime, cefotaxime, ceftazidime, cefepime, aztreonam, cefoxitin, ciprofloxacin, levofloxacin, gentamicin, amikacin, co-trimoxazole, piperacillin/tazobactam, imipenem and meropenem. Multi-drug resistance was defined as resistant to $\geq 3$ antimicrobial categories. ATCC 25922, 35,218 and 27,853 were chosen as quality control strains. Results of antibiotic susceptibility were interpreted according to CLSI guidelines, 2015 [20].

\section{Molecular characterization of antibiotic resistance genes} Carbapenemase genes (blaKPC-2, blaGES, blaIMP-4, blaVIM-1, blaNDM-1and blaOXA-48) were screened in carbapenem-resistant DEC strains (MIC $\geq 4 \mathrm{ug} / \mathrm{ml}$ to imipenem or meropenem). Positive strains were further studied by sequencing. Strains showing significantly decreased susceptibility to ceftazidime or cefotaxime $(\mathrm{MIC} \geq 32 \mathrm{ug} / \mathrm{ml}$ ) were further studied by PCR amplification and sequencing of the extended-spectrum $\beta$-lactamase genes (ESBL genes, including blaSHV, blaTEM and blaCTX-M). Isolates showing high resistance to quinolones (MIC $\geq 32 \mathrm{ug} / \mathrm{ml}$ to ciprofloxacin or levofloxacin) were further tested for amino acid changes in the plasmid-mediated quinolone-resistant genes $g y r A$ and $g y r B$, according to the methods reported by Yenkao et al. [21]. Quality control came from the strains identified by sequencing before. GenBank database (http://www.ncbi.nlm.nih.gov/) was employed to confirm the subtypes of antibiotic resistance genes.

\section{Statistical analysis}

Using the software PASW Statistics 18.0 (IBM Corporation, New York), the chi-squared $\left(x^{2}\right)$ test was employed to determine the statistical significance of data. $P$ value of $<0.05$ was considered as statistically significant.

\section{Results}

\section{Clinical features}

Between August 2015 and September 2016, 684 stool samples were collected from diarrheal children under 5 years of age. In the population studied, most children (52.0\%) were less than 24 months, $14.7 \%$ were $24-35$ months, $16.9 \%$ were 36-47 months, and $16.4 \%$ were $48-59$ months old, respectively. Boys accounted for $61.6 \%$ of the study population. Most patients were admitted in the summer (36.8\%), followed by spring (23.5\%), winter (21.6\%), and autumn (18.0\%). About half of the admitted children with acute diarrhea showed abdominal pain, followed by fever and vomiting (Details shown in Table 1).

\section{Prevalence and epidemiological characteristics of DEC among infected children}

Among 684 collected stool samples, 54 were positive for DEC (overall prevalence 7.9\%). The most frequent pathotype was EPEC (50.0\%), followed by EAEC (20.4\%), ETEC (14.8\%), EIEC (3.7\%), and STEC (3.7\%). Meanwhile, the remaining $7.4 \%$ cases were co-infected with more than one DEC pathotype $(1 \mathrm{tEPEC}$ and EAEC; 3 aEPEC and ETEC). Notably, among EPEC-infected cases, aEPEC accounted for $77.8 \%$, while tEPEC accounted for just 22.2\% (Fig. 1). Clinical data were available for 54 children with single or mixed DEC infection (shown in Additional files 1, 2 and 3). Fever was observed as the most frequent symptom (51.9\%) among DEC-infected children, followed by vomiting (25.9\%), abdominal pain (11.1\%), bloody diarrhea (7.4\%), and nausea (3.7\%). Two children infected with non-O157:H7 STEC, both had bloody stools and showed severe

Table 1 Basic information and clinical symptoms of the 684 children with acute diarrhea

\begin{tabular}{ll}
\hline Characteristic & Number (\%) \\
\hline Age(months) & $166(24.3 \%)$ \\
$0-11$ & $189(27.7 \%)$ \\
$12-23$ & $101(14.7 \%)$ \\
$24-35$ & $116(16.9 \%)$ \\
$36-47$ & $112(16.4 \%)$ \\
$48-59$ & \\
Sex & $421(61.6 \%)$ \\
Male & $263(38.4 \%)$ \\
Female & \\
Season & $161(23.5 \%)$ \\
Spring(January-March) & $252(36.8 \%)$ \\
Summer(April-June) & $123(18.0 \%)$ \\
Autumn(July-September) & $148(21.6 \%)$ \\
Winter(October-December) & \\
Clinical Symptoms & $60(10.8 \%)$ \\
Nausea & $114(20.6 \%)$ \\
Vomiting & $268(48.3 \%)$ \\
Abdominal pain & $97(17.4 \%)$ \\
Fever(> 37.2 $\left.{ }^{\circ} \mathrm{C}\right)$ & $16(2.9 \%)$ \\
\hline others &
\end{tabular}



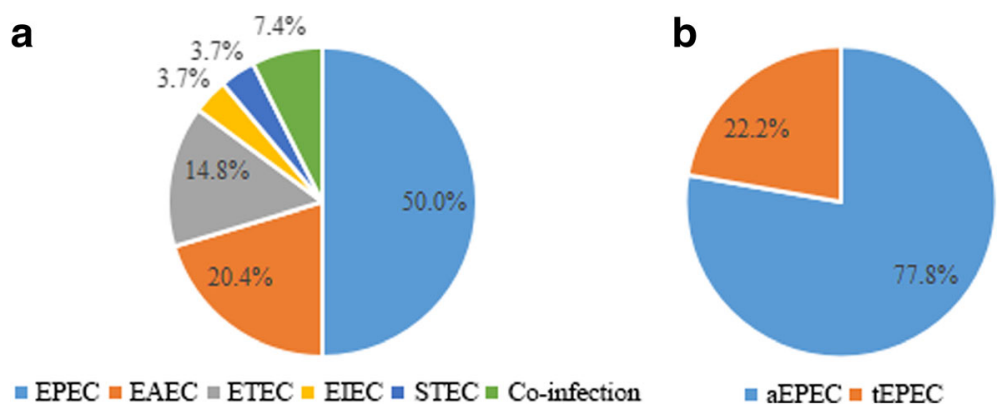

Fig. 1 Distribution of DEC strains. a Pathotype distribution of 54 DEC strains. The colorful parts of pie chart showed the percentage of different DEC pathotypes. b Subtype distribution of 27 EPEC strains. The colorful parts of pie chart showed the percentage of different EPEC subtypes

symptoms of diarrhea. Worse symptoms were also discovered in children infected with more than one DEC pathotype.

Demography analysis showed that the younger the child was, the more prone to infection by DEC (chisquared test, $P<0.001)$. When age stratification was done, the frequencies of DEC diarrheal episodes occurring in different age groups were $17.5 \%$ (0-11 months), $6.3 \%$ (12-23 months), 5.0\% (24-35 months), 5.2\% (36-47 months), and $1.8 \%$ (48-59 months) (Fig. 2). The isolate rate of DEC and the isolate number in subgroups by seasonality are shown in Fig. 3. The isolation rate of DEC showed a distinct seasonal variation, with a higher rate in the summer (7.1\%) and autumn (17.1\%) months (chi-squared test, $P=0.002$ ). In addition, EPEC, the most dominant pathotype, tended to occur more in children less than 24 months of age $(66.7 \%)$ and in the summer/autumn period (81.5\%).

\section{Serotypes of EPEC and diagnosis of 0157:H7}

Among the 27 EPEC strains, only 11 (40.7\%, 11/27) strains belonged to the classic EPEC serogroups, accounting for $33.3 \%(7 / 21)$ of aEPEC strains and $66.7 \%(4 / 6)$ of tEPEC strains. Furthermore, $22.2 \%$ strains belonged to serotype O86:k61; 11.1\%, to O55:K59; and 7.4\%, to O125:K70.

\section{Antibiotic resistance of DEC}

The observed prevalence of resistance to 16 antibiotics amongst DEC are shown in Fig. 4. The highest resistance rate was detected for ampicillin (77.8\%), followed by $64.8 \%$ for co-trimoxazole, $59.3 \%$ for cefazolin and cefuroxime; $57.4 \%$ for cefotaxime; $50.0 \%$ for ciprofloxacin; and $\geq 30 \%$ for gentamicin, aztreonam, levofloxacin, cefepime, and ceftazidime. For other antibiotics tested, cefoxitin, amikacin, piperacillin/tazobactam, imipenem, and meropenem showed efficacy against most DEC strains, with the resistance rate being $<30 \%$. Although more than $90 \%$ DEC showed sensitivity to carbapenems, there was a 9.3\% resistance rate. In addition, 36 (66.7\%) isolates of DEC were multidrug-resistant, and 1 ETEC isolate showed resistance to all the antibiotics tested; this highlights the increasing trend of extensively drugresistant bacteria. aEPEC, sharing high prevalence among DEC-infected patients, also had a high resistance rate, e.g., $81.0 \%$ for ampicillin, $66.7 \%$ for co-trimoxazole, and $14.3 \%$ for carbapenems (Fig. 4).

\section{Molecular analysis of antibiotic resistance genes among DEC strains}

Among 5 (9.3\%) carbapenem-resistant DEC strains, 3 $(60 \%)$ isolates were positive for carbapenemase genes,

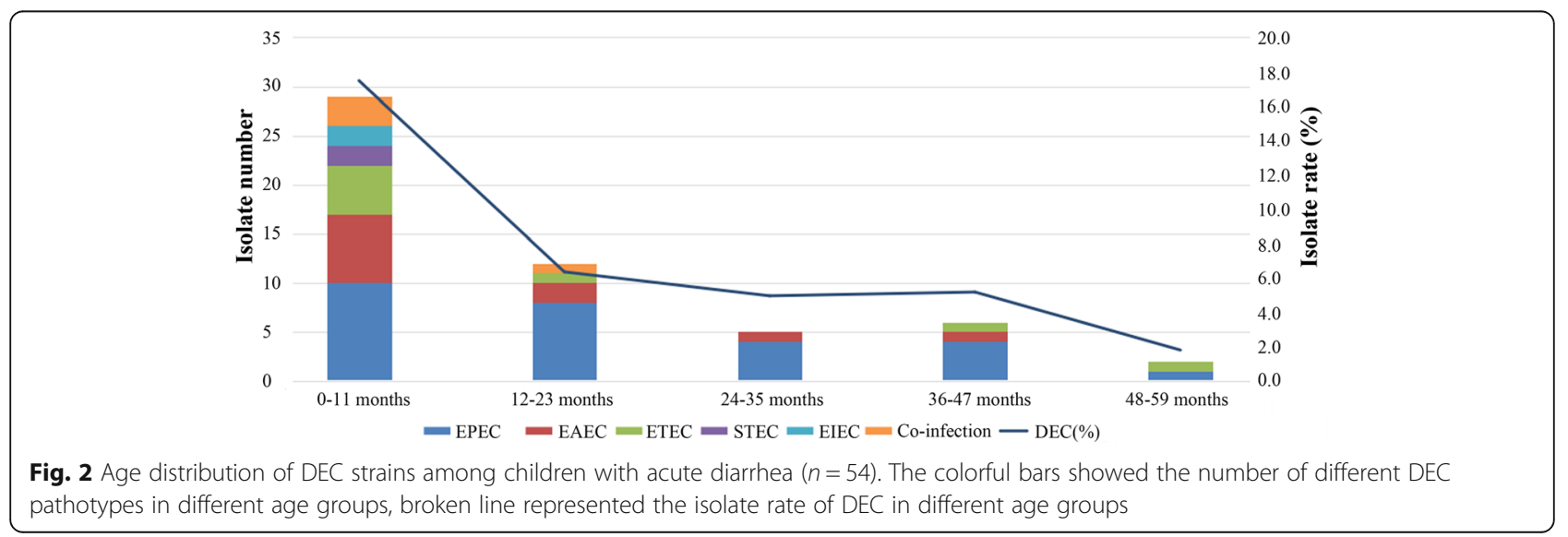




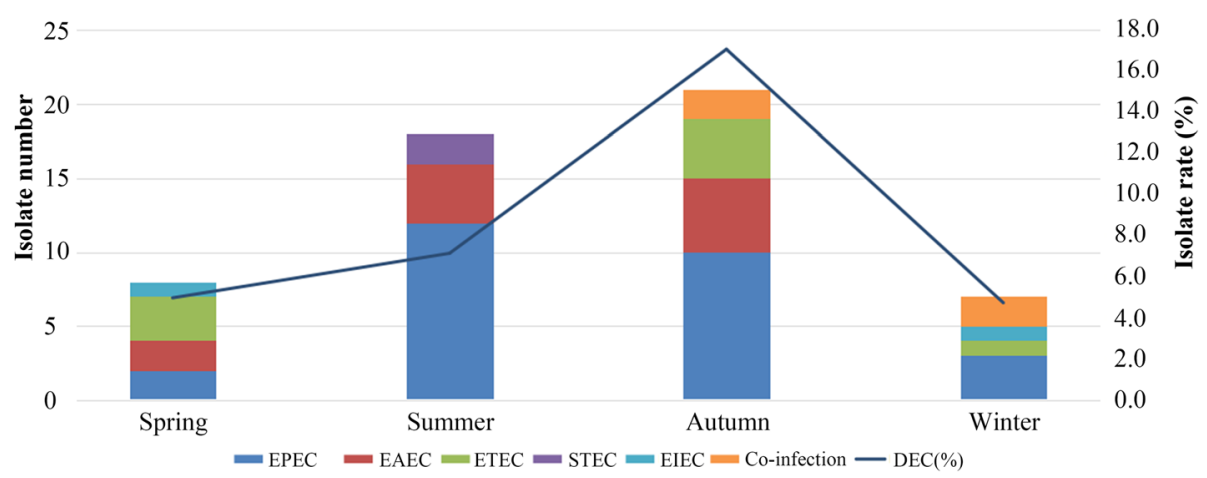

Fig. 3 Seasonal distribution of DEC strains among children with acute diarrhea $(n=54)$. The colorful bars showed the number of different DEC pathotypes in different seasons, broken line represented the isolate rate of DEC in different seasons

with 2 harboring blaNDM-1 and 1 harboring blaKPC-2 (Table 2). One EIEC strain, harboring blaKPC-2, blaCTX$M-65$, and blaTEM-1, showed resistance to most antibiotics tested, and was sensitive only to amikacin. Both blaNDM1-positive strains showing high resistance to imipenem and meropenem $(\mathrm{MIC} \geq 128 \mathrm{ug} / \mathrm{ml}$ ) were aEPEC. There were $30(55.5 \%)$ DEC isolates displaying high resistance to ceftazidime or cefotaxime (MIC $\geq 32 \mathrm{ug} / \mathrm{ml}$ ). Among them, 93.3\% were positive for ESBL genes, with blaTEM-1 (43.3\%) and blaCTX-M-55 (33.3\%) being the most common types. Positive rates of other ESBL genes detected were $20.0 \%$ for blaCTX-M-15, 10.0\% each for blaCTX-M-14 and
blaTEM-214, and 3.3\% each for blaCTX-M-65 and blaCTX-M-137. blaAmpC genes and other carbapenemase genes were not observed. In addition, 16 (29.6\%) isolates of DEC were found to be highly resistant to ciprofloxacin or levofloxacin (MIC $\geq 32 \mathrm{ug} / \mathrm{ml}$ ), but no $g y r A$ or gyrB genes were observed. Notably, aEPEC strains were found to harbor drug-resistance genes at a high rate. Among 3 carbapenemase-positive DEC strains, 2 strains positive for blaNDM-1 were aEPEC, accounting for $66.7 \%$ of carbapenem-resistant aEPEC isolates. Meanwhile, $52.4 \%$ of cephalosporin-resistant aEPEC strains were positive for ESBL genes.

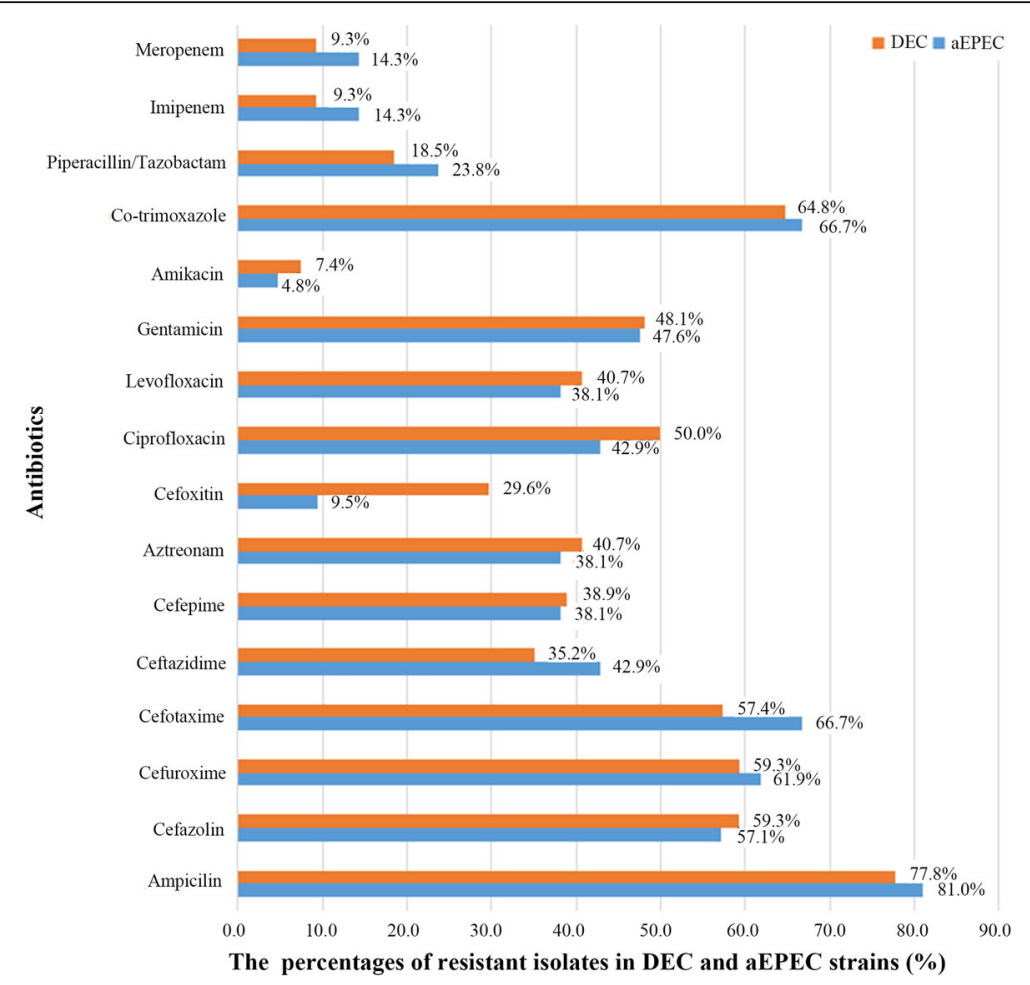

Fig. 4 Drug resistance of DEC strains $(n=54)$ and aEPEC subtype $(n=21)$. The bars showed the percentages of resistant isolates of DEC and aEPEC subtype 
Table 2 Antibiotic resistance genes of 54 DEC strains

\begin{tabular}{|c|c|c|c|c|c|}
\hline & Sex & Age(month) & Seasonality & Carbapenemase genes & ESBLs genes \\
\hline \multicolumn{6}{|c|}{$\operatorname{EPEC}(16 / 27)$} \\
\hline \multicolumn{6}{|c|}{ aEPEC(12/21) } \\
\hline TJ1 & Female & $12-23$ & Autumn & blaNDM-1 & blactX-M-55 \\
\hline TJ2 & Male & $0-11$ & Autumn & & blaTEM-1 \\
\hline TJ3 & Female & $12-23$ & Summer & & blactX-M-14 \\
\hline TJ4 & Female & $0-11$ & Winter & & blaTEM-1 \\
\hline TJ5 & Male & $12-23$ & Winter & & blactX-M-55 \\
\hline TJ6 & Male & $24-35$ & Autumn & & blaCTX-M-137;blaTEM-1 \\
\hline TJ7 & Male & $24-35$ & Autumn & & blaCTX-M-14;blaTEM-1 \\
\hline TJ8 & Male & $36-47$ & Autumn & & blaCTX-M-55;blaTEM-1 \\
\hline TJ9 & Male & $36-47$ & Autumn & & blactX-M-15 \\
\hline TJ10 & Male & $0-11$ & Summer & & blaTEM-214 \\
\hline TJ11 & Male & $48-59$ & Winter & blaNDM-1 & \\
\hline TJ12 & Male & $0-11$ & Autumn & & blaTEM-1 \\
\hline \multicolumn{6}{|c|}{$\mathrm{tEPEC}(4 / 6)$} \\
\hline TJ13 & Female & $24-35$ & Summer & & blactX-M-15 \\
\hline TJ14 & Male & $0-11$ & Summer & & blaTEM-1 \\
\hline TJ15 & Male & $36-47$ & Autumn & & blactX-M-55 \\
\hline TJ16 & Female & $24-35$ & Summer & & blaTEM-1 \\
\hline \multicolumn{6}{|c|}{$\operatorname{EAEC}(3 / 11)$} \\
\hline TJ17 & Male & $0-11$ & Autumn & & blaCTX-M-55;blaTEM-214 \\
\hline TJ18 & Female & $0-11$ & Autumn & & blaCTX-M-55;blaTEM-214 \\
\hline TJ19 & Male & $24-35$ & Autumn & & blaCTX-M-55;blaTEM-1 \\
\hline \multicolumn{6}{|c|}{$\operatorname{ETEC}(3 / 8)$} \\
\hline TJ20 & Male & $0-11$ & Autumn & & blactX-M-15 \\
\hline TJ21 & Male & $36-47$ & Winter & & blactX-M-15 \\
\hline TJ22 & Male & $48-59$ & Autumn & & blaCTX-M-55;blaTEM-1 \\
\hline \multicolumn{6}{|c|}{$\operatorname{EIEC}(1 / 2)$} \\
\hline TJ23 & Male & $0-11$ & Spring & blaKPC-2 & blaCTX-M-65;blaTEM-1 \\
\hline \multicolumn{6}{|c|}{$\operatorname{STEC}(2 / 2)$} \\
\hline TJ24 & Female & $0-11$ & Summer & & blaCTX-M-15;blaTEM-1 \\
\hline TJ25 & Male & $0-11$ & Summer & & blactX-M-15 \\
\hline \multicolumn{6}{|c|}{ Co-infection } \\
\hline \multicolumn{6}{|c|}{$\mathrm{aEPEC}+\operatorname{ETEC}(2 / 3)$} \\
\hline TJ26 & Male & $0-11$ & Autumn & & blactX-M-55 \\
\hline TJ27 & Male & $0-11$ & Autumn & & blactX-M-14 \\
\hline \multicolumn{6}{|c|}{ tEPEC + EAEC(1/1) } \\
\hline TJ28 & Male & $12-23$ & Winter & & blaCTX-M-55;blaTEM-1 \\
\hline
\end{tabular}

\section{Discussion}

DEC is a public health risk for children, especially in developing countries [6]. In the present study, we evaluated the prevalence of DEC categories, epidemiological characteristics, and antibiotic resistance patterns among 684 young children with acute diarrhea in central China.
Prevalence of DEC

The prevalence of DEC in our study was 7.9\% (54/684), lower than reports from other developing countries $[8,22]$ but similar to the results of studies in China $[4,19,23]$. This suggests the influence of different regions in the distribution of DEC. The primary pathotypes were EPEC 
(54.0\%) and EAEC (22.0\%), corresponding with the results reported by Wang et al. [15]. EPEC, first named in 1995 by Neter et al. [24], has been described as the most frequent DEC pathotype in many developing countries $[4,25,26]$. Our study reflected that EPEC constituted $54.0 \%$ of DEC isolates, a little higher than that reported by Yu et al. [4], which supported the need for follow-up epidemiological studies in childhood diarrhea. EAEC strains have been associated with traveler's diarrhea in both developing and industrialized countries [27, 28]. Studies carried out in Brazil and Mexico revealed EAEC to be the primary pathotype, with respective rates of $50 \%$ [12] and $52.1 \%$ [6]. In the present study, EAEC (20.5\%) ranked as the second most common DEC associated with infected children, reflecting the difference in distribution across geographical areas. STEC, a subgroup of DEC strongly related to severe human illnesses [29], continued to be uncommon. However, the infection rate was a little higher $(4.0 \%)$ in the present study compared to $0.4 \%$ in Beijing [23] and $0 \%$ in Shanghai [7]. Although no O157:H7 was observed, both STEC-infected children in this study presented with bloody stools. These findings should caution clinicians to carefully monitor the prevalence of STEC in children with severe diarrhea. Consistent with the findings of Patzi-Vargas et al. [25], EIEC was observed at a very low frequency $(4.5 \%)$.

\section{Age and seasonal distribution of DEC infection cases}

When age stratification was analyzed, the infection rate of DEC was found to decrease with age $(P<0.05)$, consistent with a report by Gomes et al. [13]. The lower prevalence in older children might be attributed to agerelated immunity, which has also been observed in other studies [22, 25]. Generally speaking, EPEC is among the most important pathogens infecting children under 2 years of age in the developing country [6,30]. Supporting this view, in the present study, $66.7 \%$ of EPEC infection cases were of children less than 24 months old. Seasonal variation was also found in DEC infection, especially in the EPEC group, which occurred most frequently in the late summer/early autumn period $(P<0.05)$. Similar seasonal patterns have also been observed in earlier studies $[15,25]$, indicating that DEC infection is strongly related to environmental factors such as temperature and humidity.

\section{High drug-resistant rate among DEC strains}

The resistance rates of DEC to first-line therapeutic drugs were high, e.g., $77.8 \%$ to ampicillin and $64.8 \%$ to co-trimoxazole, higher than the rates we reported before $[19,31]$ but lower than those reported by Chen et al., where 91.8\% DEC were resistant to ampicillin [32]. In this study, 36 (66.7\%) DEC isolates were multidrug-resistant, comparable with $70.2 \%$ in the study by Chen et al. [32]. By molecular analysis, the ESBL genes blaTEM-1 and blaCTX-M-55 were the genetic determinants responsible for resistance to cephalosporins. ESBL-producing strains have been reported to be recently changing from the blaTEM or blaSHV type to blaCTX-M [18], which was consistent with our findings. blaCTX-M-15 and blaCTX-M-14 have been the most common cephalosporin-resistant genotypes isolated from humans [33], while blaCTX-M-55 was the dominant type in the present study, followed by blaCTX-M-15 and blaCTX-M-14. The molecular characterization of the isolates suggested that blaCTX-M-55 is most closely related to blaCTX-M-15, with only a single amino acid substitution, indicating that blaCTX-M-55 might be just a derivative of blaCTX-M-15 [34]. In 2014, a nationwide investigation of ESBL- and AmpC-producing $E$. coli first reported that the incidence of blaCTX-M-55 exceeded that of blaCTX-M-15 in China [35], which warns of the prevalence of new variants of blaCTX-M. At present, carbapenems are the first option to treat ESBL-resistant strains, but the resistance rate of carbapenems (9.3\%) presented a rising trend, with all the DEC showing sensitivity to imipenem in our earlier study $[19,31]$. Carbapenem resistance in the Enterobacteriaceae is mainly attributed to the production of carbapenemases, the most common one being blaKPC [36] and the predominant one in China being blaKPC-2 [37, 38]. In our study, both blaKPC-2 and blaNDM-1 were found to be associated with carbapenem resistance among DEC. blaNDM-1, first reported in 2008, demonstrated a current and pressing example of the rapidity with which it could disseminate globally [39]. Recently, NDM-1-producing Klebsiella pneumoniae was detected from the neonatal ward in our hospital [40], which reflected the spread of this resistance gene in China. In contrast with a published finding [19], mutations in the plasmid-mediated quinolone resistance genes gyrA and gyr $B$ were not the major reason for resistance to quinolone antibiotics in the present study, suggesting that some other resistance mechanism might exist, e.g., overexpression of efflux pumps and decreased expression of outer membrane porins.

\section{aEPEC: The crucial pathotype in DEC-infected patients}

Interestingly, aEPEC was found to be the crucial subtype of EPEC, accounting for $77.8 \%$ of EPEC strains and $42.0 \%$ of DEC strains. Although the association of aEPEC with diarrhea is still controversial [6], recent epidemiological studies have suggested an increasing identification of aEPEC in both developed and developing countries [28, 41], with some strains leading to diarrheal outbreaks [42]. A study from 13 developing countries showed that aEPEC isolates were responsible for $78 \%(131 / 169)$ of EPEC cases in children [43], which was similar with our study. Nonetheless, many existed 
studies lack the discrimination between tEPEC and aEPEC $[4,15,16]$, which have made parallel contrast among different areas unavailable. Our study indicated aEPEC to be dominant and closely related with diarrhea among children, which has rarely been reported in China so far.

Hernandes et al. indicated that approximately $81 \%$ of the reported aEPEC strains did not belong to the classical EPEC serogroups, and $26.6 \%$ of them were $O$ nontypeable [44]. In the present study, only $33.3 \%(7 / 21)$ of aEPEC strains belonged to the classical EPEC serogroups, indicating that serotyping might fail to detect many aEPEC strains. However, serotyping is still frequently used in many clinical laboratories, including in China. This raises concerns regarding correct diagnosis and might need to be addressed urgently.

aEPEC strains identified in Mexico were shown to possess high antibiotic resistance [6]. Similarly, aEPEC strains isolated from a food-poisoning outbreak in China were found to have high multidrug resistance, including high resistance to both quinolones and extendedspectrum cephalosporins [45]. In our study, aEPEC strains have developed resistance to many commonly used clinical drugs. Resistance rates of aEPEC to quinolones and extended-spectrum cephalosporins were all $>30 \%$. Furthermore, 2 blaNDM-1 positive strains were both aEPEC strains. This implied that the drug resistance rate was high among aEPEC strains, warranting more attention to be focused on this critical aspect.

\section{Limitations}

This study also had several limitations. Some DEC pathotypes were too few to demonstrate any association with age and seasonal patterns, which had been shown in other studies $[15,25]$. Hence, larger sample size, extensive coverage area, and longer monitoring time are needed to yield an overall picture of DEC prevalence in childhood diarrhea. What is more, DAEC, another less well-defined pathotype, was not detected in our study for the difficulties in its identification and classification.

\section{Conclusion}

Knowledge of the etiology of diarrhea is important for epidemiological surveillance. Our findings indicated EPEC to be the dominant pathotype in DEC infection in children under 5 years of age. Meanwhile, aEPEC, which is becoming the dominant subtype of EPEC, outnumbered tEPEC. The rising tendency of drug resistance among DEC strains was observed, including the relatively efficient drugs imipenem and meropenem. Most aEPEC strains, as well as DEC, also possessed high levels of antibiotic resistance. In isolates exhibiting cephalosporin resistance, the blaTEM-1 and blaCTX$M-55$ genes were identified as the major resistance mechanisms. Meanwhile, blaKPC-2 and blaNDM-1 were the major carbapenemase genes associated with carbapenem resistance. These data call for further studies on DEC in children with diarrhea in China, as well as the need for continuous antimicrobial surveillance, with an emphasis on the rising prevalence of aEPEC.

\section{Additional files}

Additional file 1: Clinical information of DEC infected children. (XLSX 27 kb) Additional file 2: Raw data of MIC. (XLSX 24 kb)

Additional file 3: Sequencing for resistance genes. (DOCX 14 kb)

\section{Abbreviations}

aEPEC: atypical EPEC; CLSI: Clinical and Laboratory Standards Institute; DEC: Diarrheagenic Escherichia coli; EAEC: enteroaggregative E.coli; EIEC: enteroinvasive E.coli; EPEC: enteropathogenic E.coli; ESBL: extendedspectrum $\beta$-lactamase; ETEC: enterotoxigenic E.coli; Mac: MacConkey; MALDITOF MS: matrix-assisted laser desorption ionization time-of-flight mass spectrometry; MIC: Minimal inhibitory concentration; STEC: Shiga toxin-producing E.coli; tEPEC: typical EPEC

\section{Acknowledgments}

The authors would like to thank the clinical and laboratory staff of the Tongji hospital, Wuhan, China, for facilitating the collection of the stool samples. We would like to thank Editage [http://www.editage.cn] for English language editing.

\section{Funding}

This work was supported by the Infectious Diseases Control Project from Ministry of Health of China (2016zx10004207-004). The funders had no role in study design, data collection and analysis, decision to publish, or preparation of the manuscript.

\section{Availability of data and materials}

All the data on which the conclusions of the manuscript rely is presented in the main paper and Additional files 1,2 and 3 .

\section{Authors' contributions}

ZS designed the study. YH, FL and JY were responsible for recruitment, interview of the patients, samples collection and transport to the laboratory. $Y Z$ and EM were in charge of laboratory procedures. YM did the statistical analysis. YZ and $\mathrm{HZ}$ wrote the manuscript. All authors read and approved the final manuscript.

\section{Ethics approval and consent to participate}

The study protocol was approved by the Tongji Hospital ethics committee for research in health. Informed written consent was obtained from the parents or legal guardian of the patient before inclusion in the study.

\section{Consent for publication}

Not applicable.

\section{Competing interests}

The authors declare that they have no competing interests.

\section{Publisher's Note}

Springer Nature remains neutral with regard to jurisdictional claims in published maps and institutional affiliations.

Received: 24 February 2017 Accepted: 21 December 2017

Published online: 01 February 2018

\section{References}

1. Kotloff KL, Nataro JP, Blackwelder WC, Nasrin D, Farag TH, Panchalingam S, Wu Y, Sow SO, Sur D, Breiman RF, et al. Burden and aetiology of diarrhoeal disease in infants and young children in developing countries (the global enteric multicenter study, GEMS): a prospective, case-control study. Lancet. 2013;382(9888):209-22. 
2. Liu L, Johnson HL, Cousens S, Perin J, Scott S, Lawn JE, Rudan I, Campbell H, Cibulskis R, Li M, et al. Global, regional, and national causes of child mortality: an updated systematic analysis for 2010 with time trends since 2000. Lancet (London, England). 2012:379(9832):2151-61.

3. Walker CL, Rudan I, Liu L, Nair H, Theodoratou E, Bhutta ZA, O'Brien KL, Campbell H, Black RE. Global burden of childhood pneumonia and diarrhoea. Lancet (London, England). 2013;381(9875):1405-16.

4. Yu J, Jing H, Lai S, Xu W, Li M, Wu J, Liu W, Yuan Z, Chen Y, Zhao S, et al. Etiology of diarrhea among children under the age five in China: results from a five-year surveillance. J Infect. 2015;71(1):19-27.

5. Lanata CF, Fischer-Walker CL, Olascoaga AC, Torres CX, Aryee MJ, Black RE, Child health epidemiology reference Group of the World Health O, Unicef. Global causes of diarrheal disease mortality in children $<5$ years of age: a systematic review. PLoS One. 2013;8(9):e72788.

6. Canizalez-Roman A, Flores-Villasenor HM, Gonzalez-Nunez E, VelazquezRoman J, Vidal JE, Muro-Amador S, Alapizco-Castro G, Diaz-Quinonez JA, Leon-Sicairos N. Surveillance of Diarrheagenic Escherichia Coli strains isolated from diarrhea cases from children, adults and elderly at northwest of Mexico. Front Microbiol. 2016;7:1924.

7. Zhang Y, Zhao Y, Ding K, Wang X, Chen X, Liu Y, Chen Y. Analysis of bacterial pathogens causing acute diarrhea on the basis of sentinel surveillance in Shanghai, China, 2006-2011. Jpn J Infect Dis. 2014;67(4):264-8.

8. Jafari F, Garcia-Gil L, Salmanzadeh-Ahrabi S, Shokrzadeh L, Aslani MM, Pourhoseingholi MA, Derakhshan F, Zali MR. Diagnosis and prevalence of enteropathogenic bacteria in children less than 5 years of age with acute diarrhea in Tehran children's hospitals. J Infect. 2009;58(1):21-7.

9. Saeed A, Abd H, Sandstrom G. Microbial aetiology of acute diarrhoea in children under five years of age in Khartoum, Sudan. J Med Microbiol. 2015;64(Pt 4):432-7.

10. Croxen MA, Law RJ, Scholz R, Keeney KM, Wlodarska M, Finlay BB. Recent advances in understanding enteric pathogenic Escherichia Coli. Clin Microbiol Rev. 2013;26(4):822-80.

11. Zheng S, Yu F, Chen X, Cui D, Cheng Y, Xie G, Yang X, Han D, Wang Y, Zhang $W$, et al. Enteropathogens in children less than 5 years of age with acute diarrhea: a 5-year surveillance study in the southeast coast of China. BMC Infect Dis. 2016;16(1):434.

12. Dias RC, Dos Santos BC, Dos Santos LF, Vieira MA, Yamatogi RS, Mondelli AL, Sadatsune T, Sforcin JM, Gomes TA, Hernandes RT. Diarrheagenic Escherichia Coli pathotypes investigation revealed atypical enteropathogenic E. Coli as putative emerging diarrheal agents in children living in Botucatu, Sao Paulo state, Brazil. APMIS. 2016;124(4):299-308.

13. Gomes TA, Elias WP, Scaletsky IC, Guth BE, Rodrigues JF, Piazza RM, Ferreira LC, Martinez MB. Diarrheagenic Escherichia Coli. Braz J Microbiol. 2016; 47(Suppl 1):3-30.

14. Tennant SM, Tauschek M, Azzopardi K, Bigham A, Bennett-Wood V, Hartland EL, Qi W, Whittam TS, Robins-Browne RM. Characterisation of atypical enteropathogenic E. Coli strains of clinical origin. BMC Microbiol. 2009;9:117.

15. Wang X, Wang J, Sun H, Xia S, Duan R, Liang J, Xiao Y, Qiu H, Shan G, Jing H. Etiology of childhood infectious diarrhea in a developed region of China: compared to childhood diarrhea in a developing region and adult diarrhea in a developed region. PLoS One. 2015;10(11):e0142136.

16. Qu M, Deng Y, Zhang X, Liu G, Huang Y, Lin C, Li J, Yan H, Li X, Jia L, et al. Etiology of acute diarrhea due to enteropathogenic bacteria in Beijing, China. J Infect. 2012;65(3):214-22.

17. Alikhani MY, Hashemi SH, Aslani MM, Farajnia S. Prevalence and antibiotic resistance patterns of diarrheagenic Escherichia Coli isolated from adolescents and adults in Hamedan, western Iran. Iran J Microbiol. 2013;5(1):42-7.

18. Brolund A, Edquist PJ, Makitalo B, Olsson-Liljequist B, Soderblom T, Wisell KT, Giske CG. Epidemiology of extended-spectrum betalactamase-producing Escherichia Coli in Sweden 2007-2011. Clin Microbiol Infect. 2014;20(6):O344-52.

19. Tian L, Zhu X, Chen Z, Liu W, Li S, Yu W, Zhang W, Xiang X, Sun Z. Characteristics of bacterial pathogens associated with acute diarrhea in children under 5 years of age: a hospital-based cross-sectional study. BMC Infect Dis. 2016;16:253.

20. Clinical and Laboratory Standards Institute. Performance standards for antimicrobial susceptibility testing, twenty-fifth informational supplement, M100-S25. Wayne, PA: Clin Lab Stand Institute; 2015.

21. Kao CY, Wu HM, Lin WH, Tseng CC, Yan JJ, Wang MC, Teng CH, Wu J. Plasmid-mediated quinolone resistance determinants in quinolone-resistant Escherichia Coli isolated from patients with bacteremia in a university hospital in Taiwan, 2001-2015. Sci Rep. 2016;6:32281.
22. Moyo SJ, Gro N, Matee MI, Kitundu J, Myrmel H, Mylvaganam H, Maselle SY, Langeland N. Age specific aetiological agents of diarrhoea in hospitalized children aged less than five years in Dar es Salaam, Tanzania. BMC Pediatr. 2011;11:19.

23. Huang F, Deng Y, Qu M, Liu GR, Liu Y, Zhang X, Li J, Yan HQ, Gao ZY, Liu $B W$, et al. Etiological surveillance and analysis of infectious diarrhea in Beijing in year 2010. Zhonghua yu fang yi xue za zhi [Chinese journal of preventive medicine]. 2011;45(9):820-4.

24. Neter E, Westphal O, Luderitz O, Gino RM, Gorzynski EA. Demonstration of antibodies against enteropathogenic Escherichia Coli in sera of children of various ages. Pediatrics. 1955;16(6):801-8.

25. Patzi-Vargas S, Zaidi MB, Perez-Martinez I, Leon-Cen M, Michel-Ayala A, Chaussabel D, Estrada-Garcia T. Diarrheagenic Escherichia Coli carrying supplementary virulence genes are an important cause of moderate to severe diarrhoeal disease in Mexico. PLoS Negl Trop Dis. 2015;9(3):e0003510.

26. Bokhari H, Shah MA, Asad S, Akhtar S, Akram M, Wren BW. Escherichia Coli pathotypes in Pakistan from consecutive floods in 2010 and 2011. Am J Trop Med Hyg. 2013;88(3):519-25.

27. Kaur P, Chakraborti A, Asea A. Enteroaggregative Escherichia Coli: an emerging enteric food borne pathogen. Interdiscip Perspect Infect Dis. 2010:2010:254159.

28. Foster MA, lqbal J, Zhang C, McHenry R, Cleveland BE, Romero-Herazo Y, Fonnesbeck C, Payne DC, Chappell JD, Halasa N, et al. Enteropathogenic and enteroaggregative E. Coli in stools of children with acute gastroenteritis in Davidson County, Tennessee. Diagn Microbiol Infect Dis. 2015;83(3):319-24.

29. Karmali MA. Emerging public health challenges of Shiga toxin-producing Escherichia Coli related to changes in the pathogen, the population, and the environment. Clin Infect Dis. 2017;64(3):371-6.

30. Nakhjavani FA, Emaneini M, Hosseini $H$, Iman-Eini $H$, Aligholi M, Jabalameli F, Haghi-Ashtiani MT, Taherikalani M, Mirsalehian A. Molecular analysis of typical and atypical enteropathogenic Escherichia Coli (EPEC) isolated from children with diarrhoea. J Med Microbiol. 2013;62(Pt 2):191-5.

31. Zhu XH, Tian L, Cheng ZJ, Liu WY, Li S, Yu WT, Zhang WQ, Xiang X, Sun ZY. Viral and bacterial etiology of acute diarrhea among children under 5 years of age in Wuhan, China. Chin Med J. 2016;129(16):1939-44.

32. Chen Y, Chen X, Zheng S, Yu F, Kong H, Yang Q, Cui D, Chen N, Lou B, Li X, et al. Serotypes, genotypes and antimicrobial resistance patterns of human diarrhoeagenic Escherichia Coli isolates circulating in southeastern China. Clin Microbiol Infect. 2014;20(1):52-8.

33. Lv L, Partridge SR, He L, Zeng Z, He D, Ye J, Liu JH. Genetic characterization of Incl2 plasmids carrying blaCTX-M-55 spreading in both pets and food animals in China. Antimicrob Agents Chemother. 2013;57(6):2824-7.

34. Kiratisin P, Apisarnthanarak A, Saifon P, Laesripa C, Kitphati R, Mundy LM. The emergence of a novel ceftazidime-resistant CTX-M extended-spectrum beta-lactamase, CTX-M-55, in both community-onset and hospital-acquired infections in Thailand. Diagn Microbiol Infect Dis. 2007;58(3):349-55

35. Zhang J, Zheng B, Zhao L, Wei Z, Ji J, Li L, Xiao Y. Nationwide high prevalence of CTX-M and an increase of CTX-M-55 in Escherichia Coli isolated from patients with community-onset infections in Chinese county hospitals. BMC Infect Dis. 2014;14:659.

36. Cai JC, Zhang R, Hu YY, Zhou HW, Chen GX. Emergence of Escherichia Coli sequence type 131 isolates producing KPC-2 carbapenemase in China. Antimicrob Agents Chemother. 2014;58(2):1146-52.

37. Zhang F, Zhu D, Xie L, Guo X, Ni Y, Sun J. Molecular epidemiology of carbapenemase-producing Escherichia Coli and the prevalence of ST131 subclone H30 in shanghai, China. Eur J Clin Microbiol Infect Dis. 2015; 34(6):1263-9.

38. Lou Z, Qi Y, Qian X, Yang W, Wei Z. Emergence of Klebsiella Pneumoniae carbapenemase-producing Escherichia Coli sequence type 131 in Hangzhou, China. Chin Med J. 2014;127(3):528-31.

39. Johnson AP, Woodford N. Global spread of antibiotic resistance: the example of New Delhi metallo-beta-lactamase (NDM)-mediated carbapenem resistance. J Med Microbiol. 2013;62(Pt 4):499-513.

40. Yu J, Tan K, Rong Z, Wang Y, Chen Z, Zhu X, Wu L, Tan L, Xiong W, Sun Z, et al. Nosocomial outbreak of KPC-2- and NDM-1-producing Klebsiella Pneumoniae in a neonatal ward: a retrospective study. BMC Infect Dis. 2016;16(1):563.

41. Tobias J, Kassem E, Rubinstein U, Bialik A, Vutukuru SR, Navaro A, Rokney A, Valinsky L, Ephros M, Cohen D, et al. Involvement of main diarrheagenic Escherichia Coli, with emphasis on enteroaggregative $\mathrm{E}$. Coli, in severe non-epidemic pediatric diarrhea in a high-income country. BMC Infect Dis. 2015;15:79. 
42. Hu J, Torres AG. Enteropathogenic Escherichia Coli: foe or innocent bystander? Clin Microbiol Infect. 2015;21(8):729-34.

43. Ochoa TJ, Barletta F, Contreras C, Mercado E. New insights into the epidemiology of enteropathogenic Escherichia Coli infection. Trans R Soc Trop Med Hyg. 2008;102(9):852-6.

44. Hernandes RT, Elias WP, Vieira MA, Gomes TA. An overview of atypical enteropathogenic Escherichia Coli. FEMS Microbiol Lett. 2009;297(2):137-49.

45. Hao R, Qiu S, Wang Y, Yang G, Su W, Song L, Zhang J, Chen J, Jia L, Wang L, et al. Quinolone-resistant Escherichia Coli O127a:K63 serotype with an extended-spectrum-beta-lactamase phenotype from a food poisoning outbreak in China. J Clin Microbiol. 2012;50(7):2450-1.

Submit your next manuscript to BioMed Central and we will help you at every step:

- We accept pre-submission inquiries

- Our selector tool helps you to find the most relevant journal

- We provide round the clock customer support

- Convenient online submission

- Thorough peer review

- Inclusion in PubMed and all major indexing services

- Maximum visibility for your research

Submit your manuscript at www.biomedcentral.com/submit
Biomed Central 